\title{
UM POSSÍVEL SENTIDO DO DIÁLOGO LITERATURA E HISTÓRIA*
}

Marilene Weinhardt**

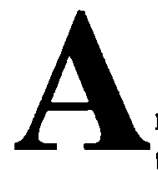

leitura de Na poética da história ${ }^{1}$ me levou a conjecturar sobre o que resultaria de um paralelo entre a visão dos viajantes estudados naquele trabalho e a dos ficcionistas nossos contemporâneos que figuram o mesmo espaço-tempo, isto é, o passado no Sul do país. Como Francisco Paz bem frisa, o espaço não é mais o mesmo depois do olhar dos viajantes. A propósito, questionei: em que medida a criação do ficcionista se condicionará por esse olhar prévio, quando e como se rebelará? Francisco afirma que o brasileiro não pode representar-se a si mesmo. Eu me perguntei: a literatura, através do seu filtro particular, não o representará?

Com alguns desvios de rota e limitações de diferentes ordens, limitações que foram se estreitando mais e mais ao longo deste texto, porque à medida que o desenvolvia ia me dando conta de que as relaçōes tomavam vulto e não era possível desenvolvê-las neste espaço, tais questionamentos estão no cerne desta proposta de diálogo. A primeira delimitação está centrada nesse genérico viajantes do primeiro momento. Aqui, tenho em vista apenas a "Dissertação Offerecida ao Instituto Historico e Geographico do Brasil" por Karl Friedrich

* A primeira versão deste trabalho foi apresentada no curso Os sentidos da viagem Semana Professor Francisco Moraes Puz, promoção do Pró-núcleo de Estudos Avançados - UFPR, 13-17 maio 1996.

** Universidade Federal do Paraná.

${ }^{1}$ PAZ, Francisco Moraes. Na poética da história. A realização da utopia nacional oitocentista. Curitiba: Editora da UFPR, 1996. 
Phillip von Martius, Carlos Frederico de Martius, como quer a publicação brasileira, datada de "Munich, 10 de janeiro de 1843", com o título de caráter prescritivo sem disfarces "Como se deve escrever a historia do Brasil", publicada na Revista desse Instituto em janeiro de $1845^{2}$ e em 1847 declarada vencedora do concurso monográfico instituído pela mesma Revista em 1840, propondo um prêmio à "melhor proposta de elaboração da história nacional."3 Destaquei as datas para frisar o quanto se tratava de um projeto caro à época, mantido ao longo da década, manutenção que naturalmente se deve ao modo de circulação de informações, mas também, talvez sobretudo, à sua importância no momento cultural.

Vale lembrar que o cientista alemão viera para o Brasil em 1817, na comitiva da imperatriz Maria Leopoldina, e por aqui permanecera, viajando pelo interior do pais durante três anos, o que lhe garantiu a fama de conhecedor da realidade brasileira. Nas palavras do historiador, esse é o "texto fundador, [...] marco zero da historiografia brasileira". ${ }^{4}$ Pergunto se não podemos pensá-lo como fundador não só em relação à fíç̧ão histórica, mas também à produção romântica, quem sabe até, mais amplamente, em relação ao conjunto mesmo da literatura brasileira. Parece-me que podemos inclui-lo naquele categoria que Michel Foucault, contrastando com os discursos que passam rapidamente, coloca "na origem de um certo número de atos novos de falas que os retomam, os transformam ou falam deles, logo, os discursos que, indefinidamente, independentemente de sua formulação, são ditos, continuam ditos, e estão ainda por dizer." ${ }^{5}$ É difícil saber quais os escritores que o leram diretamente, mas sem dúvida suas sugestões foram ouvidas e difundidas por bem mais de uma geração de intelectuais. Parece-me que aquilo que, em seu estilo incisivo e nominal, Francisco Paz chama de "sentimento de pertencimento. De brasilidade", 6 sentimento que caberia aos historiadores brasileiros a responsabilidade de desenvolver nos compatriotas, ć um projeto assumido talvez até mais claramente, ou com menos culpas, pela literatura, mais especificamente pela ficção, não só na produção da época mas, desde então até hoje, alternando períodos de consciência desse papel de forma mais acentuada com outros em que se atenua, mas nunca desaparece de todo.

O sentido de revelação que teve para mim a leitura do texto de Martius leva-me a sumariá-lo, tendo em vista sobretudo os paralelos possíveis com a história literária. Com este objetivo, a retomada da idéia central, isto é, o

${ }^{2}$ Revista do Instituto Historico e Geographico do Brasil. Rio de Janeiro, n. 24, p. 389-411, jan. 1845. As citações extraídas desse texto trarão as indicações de página no próprio corpo do trabalho.

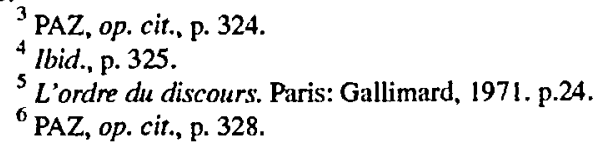


brasileiro como produto da fusão de três raças, corriqueira nos trabalhos que o citam, não é suficiente. Espero conseguir compartilhar com o leitor a minha sensação de descoberta, descoberta no sentido de perceber outros espaços de relação, outros entrelaçamentos entre a história e a ficção. A partir da leitura de "Como se deve escrever a história do Brasil", me dei conta da possibilidade de reler a ficção histórica brasileira, com manifestações tão justamente destacadas no período romântico, sob a ótica de uma proposta quanto ao modo de compor a história nacional e ao significado de fazê-lo. Intelectual do tempo da história narrativa, o texto de von Martius, pelo seu caráter didático, apresenta a súmula da teorização que está na base daquela metodologia.

Depois de breve introdução em que diz de seus propósitos, com o subtítulo "Idéas geraes sobre a Historia do Brasil", o botânico alemão ensina que quem se propõe a essa tarefa "jamais deverá perder de vista quaes os elementos que ahi concorrerão para o desenvolvimento do homem" (p. 389), elementos de natureza diversa entre si, que são as três raças, mesclando-se para cncontrar a sua feição particular. Cada raça obedece "movimento histórico caracteristico e particular". Logo, a história do povo resultante das três raças "deverá se desenvolver segundo uma lei particular das forças diagonais" (p. 391).

Chamo a atenção para a insistència, no texto de Martius, no termo particular. De seu ponto de vista europeu, mas conhecedor in loco desta porção do Novo Mundo, ficava muito claro que o processo brasileiro não podia ser julgado pelas mesmas leis que regiam o modelo do Velho Mundo. Ele entende o branco, mais especilicamente o português, como dominante, mas insiste no sentido de não se ignorar, ou mesmo minorar, as reações da cultura indígena c negra, ou índia c etiópica, conforme as denomina, sobre aqueles. Homem de seu tempo, entendendo a evolução como progresso, Martius crê na superioridade das classes privilegiadas e reafirma o princípio do aperfeiçoamento da sociedade. Quer dizer, ć só esperar pacientemente que todos terão a sua vez. Ao historiador cabe ser fillosófico e humanista, de modo a apreender a complexidade desse movimento e esclarecer aos compatriotas, para que sejam pacientes. Note-se ai que, se temos o conhecido discurso paternalista e preconceituoso na origem das teorias raciológicas que serão formuladas na Europa nos anos seguintes c logo entram em declínio, mas têm vida longa nesta terra, alcançando o século XX, temos também vislumbres da necessidade e importância de dar atenção às outras classes, aquelas que estão na base da pirâmide social, ainda que seja para dizer-lhes que esperem a sua vez, vão se comportando bem que clas também podem chegar ao topo.

Cada tópico que se segue vai apontar, pragmática e programaticamente, o que tem o historiador a pesquisar sobre cada uma dessas raças formadoras, de modo a particularizar sua contribuição e o seu modo de interação no conjunto da nova nação. 
No subtítulo "Os indios (a raça côr de cobre) e sua historia como parte da Historia do Brasil", Martius ensina: "Em primeiro logar devemos considerar o indigena brasileiro, em suas manifestações exteriores, como um ente physico, e comparal-o com os povos visinhos da mesma raça. O passo immediato nos levará á esphera da alma e da intelligencia d'estes homens; a isto se ligam investigações sobre a extensão de sua atividade espiritual, e como ella se manifesta por documentos historicos" (p. 394). O primeiro destes é a língua. Daí a viva recomendação para que se realizem estudos lingüísticos, seguidos de estudos sobre a mitologia, as teogonias e as geogonias. "Um observador philosophico não deixará de descobrir nos restos de mythos, e no balbuciamento poetico, que ainda hoje se encontram vestigios muito significativos de uma perdida philosophia natural, e de um culto ainda inigmatico. [...] dos restos actuaes de idéas e ceremonias religiosas [o historiador filosófico] conclue por noções anteriores mais puras, e por fórmas de um culto antigo..." (p. 396). Note-se que Martius propõe um trabalho eclético, criativo e imaginativo, chamando para dar sua contribuição à história, os estudos lingüísticos, etnológicos, arqueológicos e antropológicos. Os literatos deitaram e rolaram nesse espaço. Lembremos as obras indianistas de Alencar e vários dos poemas de Gonçalves Dias (Os timbiras, Poesias americanas: "Leito de folhas verdes", "I-Juca Pirama”, "Marabá", "Canção do tamoio", "O canto do guerreiro"). Entretanto, não julguemos que esses títulos resultam da lição direta de "Como se deve escrever a história do Brasil”, nem que a realização literária concorre com a histórica. Martius não descarta o rigor metodológico, frisando que os riscos da abundância de material "exige a mais severa crítica, e uma multidão de allegações extravagantes, de factos inteiramente falsos, [...] deviam ser excluidos de uma vez, e estabelecida a verdadeira base e valor historico $\mathrm{c}$ ethnographico dos povos americanos" (p. 396). Enfim, cle não descarta a possibilidade de no Brasil terem existido construções semelhantes às do México e do Peru, chamando a atenção para a necessidade da incrementação de pesquisas arqueológicas.

No subtítulo "Os portuguezes e a sua parte na Historia do Brasil", Martius enfatiza a importancia de se considerar o que a cultura e a história portuguesas têm de particular, para entender as singularidades de sua ação colonizadora, lembrando as "façanhas maritimas, commerciaes e guerreiras" (p. 399) como determinantes de diferenciação. Ainda há necessidade “de traçar um quadro dos costumes do seculo XV [...], descrever os homens taes e quaes vieram para além do oceano fundar um novo Portugal", estudar "a historia da legislação e do estado social da nação portugueza, para mostrar como n'ella se desenvolveram pouco a pouco tão liberaes instituições municipaes, como foram transplantadas para o Brasil, e quaes as causas que concorreram pra o seu aperfeiçoamento no paiz" (p. 400). É mais um assunto que, no plano literário, vai ser retomado 
programaticamente hoje. Neste item, Martius frisa a importância do estudo das relaçōes com os religiosos, particularmente com os jesuitas. Vale lembrar que Alencar dá um papel de destaque, de antagonista que não merece nenhuma simpatia do narrador, a um jesuita $\mathrm{em}$ As minas de prata. O botanico credita a supressão da Ordem dos Jesuitas em Portugal pela posição deles no Pará, enquanto na Espanha dever-se-ia a ocorrências no Paraguai, para concluir: “...de sorte que este acontecimento, que faz epoca na historia universal, se acha profundamente enraizado na historia do Brazil" (p. 402). É uma achega à concepção universalizante da história, mas é também uma inversão do percurso habitual. Nesse caso, para entender aspectos da história européia, é preciso buscar razōes na história do Novo Mundo.

Um historiador das mentalidades e do cotidiano avant la lettre está presente em recomendações como a do trecho seguinte:

O historiador deve transportar-nos á casa do colono e cidadão brasileiro; elle deve mostrar-nos como viviam nos diversos seculos, tanto nas cidades como nos estabelecimentos ruraes, como se formavam as relaçōes dos cidadãos para com seus visinhos, seus creados e escravos; e finalmente com os freguezes nas transaçōes comerciaes. Elle deve juntar-nos o estado da igreja, e escola, levar-nos para o campo, ás fazendas, roças, plantações e engenhos. Aqui deve apresentar, quaes os meios, segundo que systema, com que conhecimentos manejavam a economia rustica, lavoura e commercio colonial. Não é destituido de interesse saber-se como $\mathrm{e}$ aonde se introduziram pelos colonos, pouco a pouco, arvores e plantas europeas; como, pouco a pouco, se desenvolveu o systema presente; qual a parte que em todos esses movimentos tiveram a construção naval, a navegação e o conhecimento dos mares, principalmente d'aquelles que foram sulcados pelos portuguezes. (p. 402-3)

Ressalte-se também uma antecipação de rudimentos do conceito de longa duração. No plano literário, podem ser examinados desta perspectiva romances como Memórias de um sargento de milicias, A moreninha e, sobretudo, Inocência.

O ponto seguinte que Martius contempla é o grau de instrução, isto é, a situação do ensino, primeiro em Portugal, para depois examinar qual o legado que coube ao Brasil, destacando de modo especial, como bom humanista que é, a poesia e a retórica.

Cada vez mais vai se afirmando o caráter globalizante da proposta, em dois sentidos: a tarefa do historiador ć abordar diversos aspectos, percebendo a 
correspondência entre eles, e ainda situar cada um desses aspectos num panorama amplo, espacial e temporalmente.

A necessidade do levantamento sobre a vida militar, primeiramente na Metrópole e depois na colónia, é o próximo assunto, não esquecendo de apontar as adaptações que deve ter sofrido no Brasil, em função de suas diferenças em relação à Europa. As guerras constituem como que o assunto por excelência dos romances históricos, mas no período romântico foram relegadas a posição secundária. José de Alencar, em $O$ gaúcho, focaliza a Revolução Farroupilha, mas como episódio secundário, ainda que aproveite para opinar sobre o momento histórico; em A guerra dos mascates, que empresta o título diretamente do episódio histórico, o tempo narrativo é o que antecede o movimento, tanto que o título do último capítulo é “No qual se acaba a crônica justamente quando ia começar a guerra dos mascates". ${ }^{7}$ Atualmente há vasta produção ficcional, esteticamente bastante desigual, em que o tempo narrativo é o de lutas.

A sugestão sobre o aproveitamento das narrativas de viagem está também em Martius:

achará o historiador um attractivo variadissimo na narração das numerosas viagens de descobertas e incursões dos differentes pontos do littoral para os desertos longiquos (sic) do interior (os sertões), emprehendidas em procura de ouro e pedras preciosas, ou com o fim de captivar e levar como escravos os indigenas. Essas entradas foram pela maior parte executadas espontaneamente por pessoas [animadas de] espírito romanesco e aventureiro. (p. 403-404)

Martius sugere que esses relatos sejam buscados nos arquivos das cidades - "aventuras dignas de inspirar tanto a phantasia do poeta épico como a musa mais tranquilla do historiador" (p. 404). Note-se a comparação. A inspiração do historiador também vem da musa. Parece uma premonição, não só quanto à atual teoria histórica, que propõe que a escrita da história seja criativa, mas também quanto à ficção. $O$ aval do viajante como personagem ficcional é recurso narrativo do qual a atual fiç̧ão histórica vai usar e abusar.

$O$ cientista da uma pista sobre as possiveis descobertas desse rumo da pesquisa pelo interior, particularidade que lhe chamara a atenção:

$\mathrm{Eu}$ fallo das numerosas historias e legendas sobre as riquezas subterraneas do paiz, que n'elle são o unico elemento do roman-

${ }^{7}$ 2.ed.[São Paulo]: Melhoramentos, [s.d.] p. 320. 
tismo, e substituem para com os brasileiros os innumeros contos fabulosos de cavalleiros e espectros, os quaes fornecem nos povos curopeus uma fonte inesgotavel e sempre nova para a poesia popular. Pareceu-me que a superstição do povo se tinha por assim dizer, concentrado n'esses contos, e para assignar-lhes seu verdadeiro valor, o historiador não deixara de ponderar emquanto os negros contribuiram para essas, ás vezes summamente poéticas narrações. (p. 404)

Segue-se o levantamento das características do negro que contribuem para alimentar essas narrações (gosto de falar, fetichismo), enquanto os índios alimentam a fantasia com monstros fantásticos. Uma abordagem que tenha em vista tais fontes de fantasia pode ser rentável para a história da literatura. Um levantamento tendo em vista essa perspectiva talvez chegue a perceber um ciclo em que domina a fantasia curopéia (castelos, cavaleiros, espectros), um ciclo alimentado pelas riquezas subterrâneas e outro pelos seres fantásticos. Pode ser um caminho para uma história da temática do maravilhoso na literatura nacional.

Essa contribuição da cultura negra é a deixa que Martius emprega para passar ao subtitulo subseqüente: "A raça Africana em suas relaçōes para com a historia do Brazil". As recomendações quanto à importância de pesquisas para determinar que negros vieram e qual seu passado cultural são do mesmo teor daquelas feitas em relação ao português e ao indio. Merecem destaque aqui os cuidados do cientista para não corroborar os lugares-comuns sobre a inferioridade da raça e os conseqüentes prejuizos que a miscigenação teria trazido aos brasileiros, o que poderia jogar por terra a teoria que defende desde o início quanto ao progressivo melhoramento da nova etnia surgida da fusão das anteriores, ao mesmo tempo em que não poderia questionar abertamente a teoria da inferioridade, porque aí estaria questionando também o sistema escravista como instituição, atitude que, no quadro político-social da época, equivaleria a contestar instituição mais alta, isto é, o próprio Império. No plano ideológico, Martius cra não só um conservador como também um ardoroso defensor da Monarquia, tônica do final de seu texto, que precisa ser lido sem perder de vista a herança iluminista de sua formação. Observe-se como a questão é deixada em aberto, à responsabilidade do historiador, no torneio frasal $\mathrm{em}$ que reafirma a decisiva influência dos negros, mas acentua que só o levantamento e a análisc permitirão ao historiador concluir se foi para o melhor ou pior "desenvolvimento civil, moral e politico da presente população" (p. 405). Sublinha-se ainda a necessidade de examinar a presença de Portugal na África. Ou seja, se a conclusāo sobre a cultura negra for muito desfavorável, uma saida possivel é atenuar sua presença encarecendo a influência de Portugal ainda no período africano. A criação literária da época não ousou muito mais. A própria escrava 
Isaura, personagem de Bernardo Guimarães no romance homônimo, era branca. Alencar escreve uma peça dramática levada à cena em 1860, intitulada Mãe, em que uma mulata escrava servia ao filho branco como senhor. O desfecho é trágico. Ela se envenena na hora do reconhecimento, para que ele não seja penalizado socialmente. A crítica da época foi favorável, mas colocou em destaque a questão da maternidade, não a da escravidão. ${ }^{8}$

Ainda um traço a considerar na proposta de Martius é a recusa de uma história factual, quando julga condenável um "certo espirito de chronicas" (p. 407) das histórias provinciais, o que lhe dá entrada na discussão sobre o regionalismo, com implicações na história e na criação literária. Entre os dois perigos apontados - fazer a história das províncias ou desprezar as particularidades - "risco de não accertar com este tom local que é indispensável onde se trata de despertar no leitor um vivo interesse, e dar ás suas descripçōes aquella energia plastica, imprimir-lhe aquelle fogo, que tanto admiramos nos grandes historiadores" (p. 408) - a saida apontada é a regionalização "por analogia da sua natureza physica" (p. 408). Daí a necessidade de o historiador conhecer de fato o país, porque o conhecimento parcial produz distorções, não permitindo a identificação da diversidade.

Mais uma vez, se encarece a viagem. Pensemos novamente no projeto alencariano de retratar as regiões do pais, com $O$ sertanejo e $O$ gaúcho, e nos sertanistas Bernardo Guimarães (O garimpeiro), Taunay (Inocência) e Franklin Távora ( $A$ casa de palha). O que faltou a Alencar, segundo muitos críticos, foi justamente a viagem, malogradamente procurando compensá-la com a imaginação. A "pintura da natureza" é fundamental para bem apresentar os fatos históricos, ensina Martius. Note-se que não se trata de uma proposta determinista quando a teoria apenas começava a tomar forma, mas do reconhecimento da importância do cenário. Ainda é a produção alencariana indianista e regionalista o exemplo mais acabado, ainda que os outros escritores românticos não tenham ignorado a lição, não se tenham furtado à pintura da natureza, freqüentemente atendendo a esse projeto em detrimento do estético. Valendo-se da liberdade de ficcionistas, também não hesitaram em criar quadros da natureza, dispensando o cmpirismo. Para um historiador aparelhado com esses predicados, Martius aponta uma tarefa pragmática e imediata: "dar uteis conselhos á administração" (p. 409). É a ponte para passar à conclusão, apoiando vivamente a monarquia como forma de governo. Quem sabe quanto tal intromissão nos assuntos políticos locais e presentes terá definido a sorte da "Dissertação" do botânico.

Friso que não estou propondo uma leitura do texto histórico e do literário como equivalentes. Cada um guarda suas funções específicas. No entanto, a

${ }^{8}$ MENESES, Raimundo de. José de Alencar: literato e politico. 2.ed. Rio de Janciro: Livros Técnicos e Científicos, 1977, p. 149-52. 
aproximação, os pontos de contato, não são uma invenção dos últimos anos. Em certas épocas o parentesco é orgulhosamente proclamado, em outras uma das duas arvora-se em prima rica e ignora a outra ou ordena-lhe que use a porta de serviço, mas a relação é antiga.

\section{RESUMO}

Este trabalho sumaria a dissertação do botânico alemão Karl Friedrich Phillip von Martius intitulada "Como se deve escrever a história do Brasil", datada de 1843, e comenta-a tendo em vista a possibilidade de ler a história da produção literária pelo viés daquela proposta de escrita da história nacional.

Palavras-chave: literatura e História, século XIX.

\section{RESUME}

Ce travail résume la dissértation du botanique allemand Karl Friedrich Phillip von Martius intitulée "Como se deve escrever a história do Brasil" ("Comment on doit écrire l'histoire du Brésil"), datée de 1843. Le but du commentaire est d"examiner la possibilité de lire l'histoire de la production littéraire envisagée du point de vue de cette proposition de l'écriture de l'histoire national.

\section{REFERÊNCIAS BIBLIOGRÁFICAS}

ALENCAR, José de. As minas de prata. 2.ed. [São Paulo]: Melhoramentos, [s.d.].

FOUCAULT, Michel. L'ordre du discours. Paris: Gallimard, 1971.

MARTIUS, Karl Friedrich Phillip von. Como se deve escrever a história do Brasil. Revista do Instituto Historico e Geographico do Brasil. Rio de Janeiro, n. 24, p. 389-411, jan. 1845.

MENESES, Raimundo de. José de Alencar: literato e político. 2.ed. Rio de Janeiro: Livros Técnicos e Científicos, 1977.

PAZ, Francisco Moraes. Na poética da história. A realização da utopia nacional oitocentista. Curitiba: Editora da UFPR, 1996. 